\title{
A New Approach to Improve the Critical Thinking Abilities and Communication Skills of Undergraduate Science Students
}

\author{
Maura Grealy \\ Pharmacology \& Therapeutics, School of \\ Medicine, National University of Ireland, \\ Galway, Ireland
}

\begin{abstract}
This study explores a new approach to improving the communication skills and critical thinking ability of undergraduate science students. In the past we have relied on didactic methods to impart knowledge to undergraduate students. Development of critical thinking skills was allowed to grow organically as the students progressed through the undergraduate years. With the advent of online availability of information and therefore easy access to information the significance of knowledge acquisition is no longer as important as the ability to analyse information critically and communicate it. With this in mind we have introduced an "Introduction to Communication" module into the first year undergraduate course in Biomedical Science. This module exposes student to oral and written communication skills from the very outset. They are guided on literature searches and use of information. By the second semester they use the skills of literature search and selection to research topics which are presented in the form of a debate which hones skills of critical thinking. This study looks at how it affects the first year student experience, the perceived benefits from the student perspective and the perceived benefits from faculty. Survey analysis both at the completion of first year and at the end of the first semester in the second year have revealed that the students have benefited significantly from the approach. It was clear that the appreciation of the benefit accrued was in many cases only realised in the second year of study. The work informs our future direction in this venture
\end{abstract}

\section{Introduction}

Debate as an academic exercise has been used for generations to inspire critical thinking, to engage discussion and to put forward new ideas. In recent decades it has been used as a pedagogical method with the aim of improving critical thinking

\author{
Lynn O’Connor \\ Biomedical Science, School of Medicine, \\ National University of Ireland, Galway, \\ Ireland
}

and oral communication skills [1,2,3]. A number of recent trends in educational assessment methods have resulted in moving away from the discussion/debate as a method of teaching and learning because of the difficulties in transparent evaluation, the need for detailed marking schemes, the facility of the PowerPoint lecture and in many cases lack of academic mentors to tutor groups of debating students. It has been shown that students involved in debate benefit in many ways including critical thinking skills [3] retention of information [4] and increasing awareness of important issues in the their relevant field of study [5]. Significantly, studies comparing debates versus lectures as teaching strategies find that students exposed to debates outperform their peers on assessments examining comprehension of concepts [5].

The aim of this work was i) to give students the skills necessary to improve their own communication skills ii) to introduce scientific debate into the first year of a Biomedical Science programme and to evaluate whether the stated benefits justified the academic commitment and iii) to evaluate the impact of debate topic on the student experience. Debate presentations were held in the second semester. First semester was dedicated to introducing the skills of literature search and selection and honing oral communication skills. We present here data to suggest that this module was successful in achieving its aims and evidence to suggest that the benefits of this module would be beneficial in all first year science courses

\section{Methods}

The class used for this study comprised 59 first year university students on a Biomedical Science programme. This is a high entry points course and 
this student cohort fall in the top $10 \%$ of the national average achievement scores. Most debate teams comprised four students pro and four students contra the motion in a modified LincolnDouglas debate format [6].

Students were introduced to literature search techniques and skills in semester one, two weeks after they entered the University. These classes were convened in a computer suite where all students had access to online search programmes. EndNote (Thomson Reuters, Version x3) was routinely employed to teach the students how to search online databases, organise and store retrieved references and how to create bibliographies. This programme was also used to explore various publishing styles.

The semester one component of this module included a component on the design and delivery of a multimedia presentation using PowerPoint (Microsoft ${ }^{\circledR}$ Office 365). The focus here was on the quality of the slides and the communication between student and the audience.

In semester two one academic met with each team on a weekly basis for guidance. On debate day the academic tutor along with two other academics assessed the students. 25\% of the overall marks was individual and came from self/peer assessment; another $25 \%$ individual component was based on the presentation on debating day - contribution to the overall effort and attendance/engagement at pre-arranged meetings with tutor throughout the preparation weeks. $50 \%$ of the final mark was a group mark and was based on the strength of the argument and the quality of the overall effort.

Students were surveyed using the survey function on the online portal Blackboard.

\section{Results and Discussion}

At the completion of the debate module the students were surveyed for their evaluation of the experience. The same students were surveyed at the end of semester one of the second year of the course. The first year course outline of this science degree is like many other first year science programmes worldwide - a broad-based introduction to biology, chemistry and physics. It is not until the second year that students have an opportunity to explore in more detail the molecular aspects of biochemistry, pharmacology and physiology which represent three of the four major subject options in this degree programme. It was our belief that it was only when they began to study these subjects that they would more fully appreciate the value of a molecular-based debate topic. We were interested to see if their opinions had changed between end of semester two in Year 1 and the end of semester one in Year 2. To prevent bias the students were given an opportunity to provide open answers to the questions posed along with questions in a multiple choice format.

"Working as part of a team" and "the whole experience on debate day" jointly ranked highest in answer to a question which asked "what did you like most about the debates?" The top ranking comments were

1. Working as part of a team

2. The experience on the day

3. Meeting other people on our course

4. Interesting topics

5. Learned a lot

6. Experience at public speaking

When asked "What did you like least about the Debates" the top answers were

1. Unequal standard of topics

2. Public Speaking

3. The cross-examinations

4. Peer-marking

5. Team work

6. Deadline pressure

When tutors were asked to give their overall impression of the module the following were the most common responses

1. Tremendous and passionate student engagement at the debate during the $\mathrm{Q}$ \& A open session which followed the formal debate by the teams on any day

2. The students enjoyed the process

3. The students all knew each other

4. Quality of the presentations improved from the beginning to the end

5. Students were well informed on their topic

6. Student demonstrated newly acquired literature review skills and referencing skills and were able to put them into practice

The "unequal standard of topic" referred to some groups debating molecular topics while other groups debated social topics which were viewed by the students as less challenging. At the end of semester one in the second year of this course we re-evaluated the student opinion of their first year work. Figure 1 shows the results of the satisfaction rating (at the time of the assignment) from students given a social topic and Fig 2 shows the satisfaction rating of students given a scientific/molecular topic. 


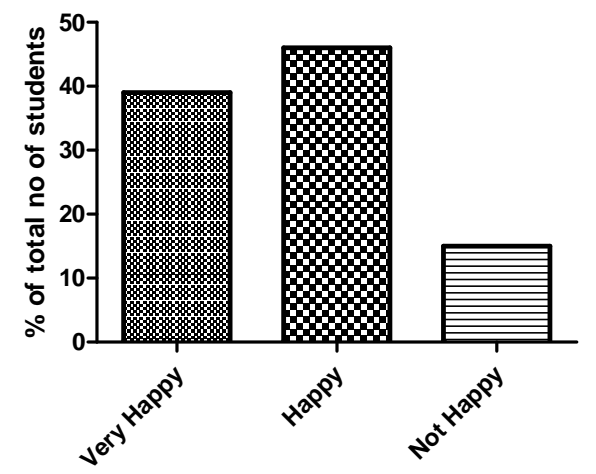

Figure 1. Satisfaction Rating of Students who were given a social topic for their Debate Assignment

It is clear from the data presented that students were happier when presented with a social topic rather than a molecular topic for the debate. From the data presented in Fig 1 and Fig 2 it is evident that while $39 \%$ of students who received a social topic were very happy with it, only $8 \%$ of students who received a molecular topic gave the same satisfaction rating. On the other hand the percentage of students who were happy overall (assessed by combining happy and very happy) with their assigned topic was very similar for both groups with $85 \%$ happy with the social topic and 81\% happy with the molecular topic. From this we have deduced that while students in general liked the topics that they were given they still perceived that the molecular topics were more difficult that the social topics.

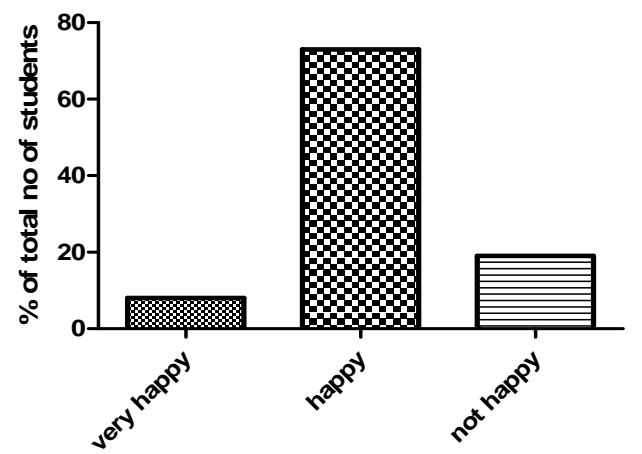

Figure 2. Satisfaction Rating of Students given a molecular topic for their Debate assignment
Students were surveyed to determine if they thought the molecular topics were useful to them in the subsequent year of their course when they began to study the molecular topics.

Fig 3 shows the results of this survey. 8\% of those who did have a molecular topic thought it helped their current course to a major extent. 65\% thought it helped a little while $27 \%$ did not see any benefit. From a faculty perspective these data were gratifying; revealing, that in all, $73 \%$ of these students gained some knowledge benefit from the first year debate module.

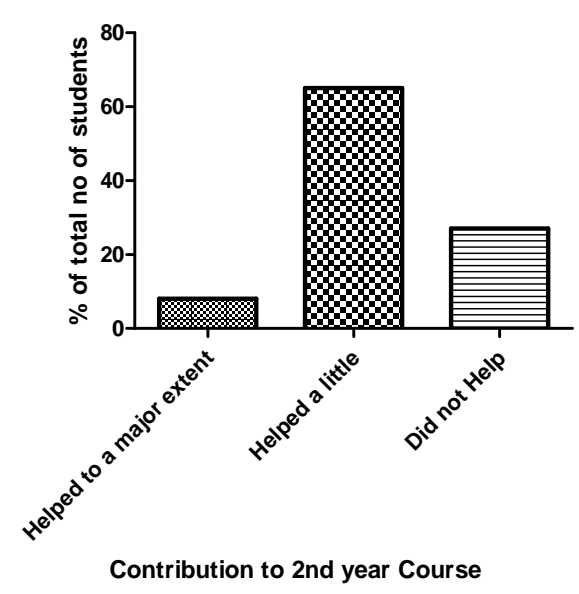

Figure 3. Surveyed-opinion of students in second year regarding the contribution of first year assignment to second year academic content

Students who researched a social topic were also surveyed to determine if they felt that a molecular topic would have benefited them better in their second year modules. The results of that opinion poll are summarized in Fig 4. It is clear from the data obtained that in total $54 \%$ of students who had a social topic valued the molecular topic as preparation for the $2^{\text {nd }}$ year subjects. There are 25 respondents altogether in this group compared to 26 in the second group. 19\% of this group strongly agreed that studying a molecular topic for the debate would have provided them with longer term benefit while $35 \%$ of this group agreed with this statement. In total $73 \%$ of the molecular debate students and $54 \%$ of the social debate students thought it was more worthwhile having a molecular topic. This represents approx $63 \%$ of the total 
class. This figure compares very favourably with the percentage of students that thought the molecular topic was harder when surveyed in the direct aftermath of the module. This information is interesting because it allows faculty to relate this information to subsequent groups of incoming students who might also feel aggrieved at being assigned with what they perceive to be a difficult molecular topic.

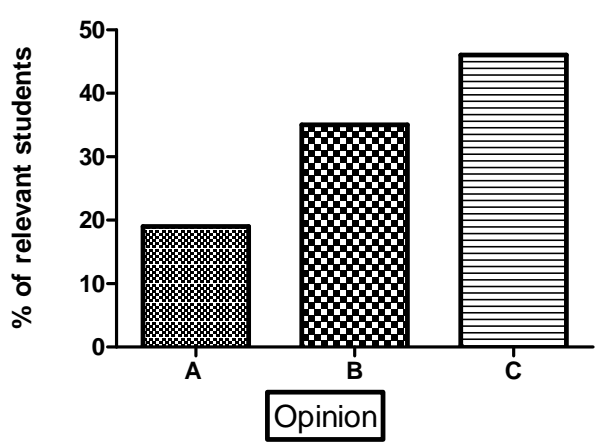

Figure 4. Students who had researched a social topic were asked whether they agreed with the statement "I think a molecular topic in first year would have been more beneficial to me this year than the social topic I researched". A is "Strongly agree with the statement", B is "I agree with the statement" and $C$ is "disagree with the statement"

From the data accumulated it is clear that overall it was a very positive experience for the students at many levels. Public speaking was high on the list of items most loved and hated in this model. We made every effort to ensure that it was conducted in such a way to make it comfortable for those students that had never taken part in public speaking in the past and to enable other more confident speakers to stretch themselves and grow. Our efforts included supervised practice of the debate presentation over a two week period prior to the debate. In addition, in the weeks prior to presentation the students practiced the process of rebuttals and cross examination with their team members and academic tutor. Tutors also acted as devil's advocate on these occasions and over that practice period the students grew more confident in their work and in the presentation of the work. The format of the debates allowed for use of
PowerPoint presentation as props. The use of PowerPoint was part of the overall "Introduction to Science Communication" module that the students learned in the first semester of their first year. We believe that this made the presentation task more comfortable for the students and in particular for those students that had never previously taken part in public speaking. This had the added advantage of giving the students first-hand experience of preparing and delivering a PowerPoint presentation. While the first-time presenters tended to use the slides as backup to a large extend the students who were more confident were able to rely on their own oral delivery to a greater extent. In this way we believe that the ability of each student was catered to and allowed each student to stretch themselves as far as they were confident to go. An additional advantage of using PowerPoint slides was that the judging panel were able to assess visibly, the bibliographic sources used, the quality of which was part of the assessment.

The data illustrate that the single biggest challenge of using debates as a pedagogical tool is selecting topics that the students believe are of equal challenge. In this instance we divided the topics into ethical and molecular. Ethical topics used included i) We are past the time in history when we need to use animals in Biomedical research ii) Recreational drugs should be legalised iii) Addiction - we should penalise not treat. Molecular topics included i) ATP is the single most important molecule in human metabolism ii) PCR has contributed more to medical diagnosis in the last twenty years than any other single development iii) Obesity can be explained solely by the first law of thermodynamics. In $70 \%$ of cases, the students believed that the molecular topics were harder and therefore that they were disadvantaged. $30 \%$ of the students however saw the molecular topics as more relevant to their course of study. However we believe that a mixture of both ethical and molecular issues contributed to the overall success of the module.

As a pedagogical tool the debate has been used to improve critical thinking of the students and we believe that these targets are being met here along with improvements in oral communication skills $[1,2,3]$.

One of the issues we are interested in is whether these skills introduced at an early stage in $3^{\text {rd }}$ level education will improve skills of concentration, memory retention [4] and performance at examination [5]. A central issue we are working towards is improving the critical thinking skills of 
the students. We are currently working on metrics to examine this as this cohort moves through the academic system.

It is difficult to design a metric to evaluate whether critical thinking has improved in a student population. However, we did look to the end of semester overall scores in examinations to determine if we could detect any correlation between examination scores and type of module. The rationale although somewhat subjective was that the molecular topics would confer a higher level understanding of the learning in this area which would translate into examination scores. Of the top $10 \%$ in the class in the end of year examinations, 33.4\% had researched a social topic and $66.6 \%$ had researched a molecular topic. This trend was mirrored when we looked at the top $20 \%$ of the class. The bottom $10 \%$ of the class was reciprocally related with $33.4 \%$ having studied a molecular topic and $66.6 \%$ a social topic. Interestingly when we extend the analysis to the bottom $20 \%$ of the class, $66.6 \%$ of the class had researched a social topic and $33.4 \%$ had researched a molecular topic. It is tempting to speculate that the experience of researching in the molecular science area enhanced the students' examination performance by enhancing their critical thinking and hence learning ability. However, we would need significantly more data and data acquisition over a longer period of time to confirm this finding. Student engagement was heightened in the question and answer sessions following each debate presentation on the ethical issues as the students were more confident in these topics. This level of engagement was extremely gratifying at a time when it is frequently very difficult to engage students. The student-led discussions that followed were engaging, insightful and fun for the students. There are challenges that we need to overcome to change the perception that topics confer differential workloads and therefore unfair advantage / disadvantage on affected students. However the mixed topics have such advantages to the overall experience that we intend to continue with them in the coming year. With the knowledge gained from the student survey we can proactively address the issue at the start of the module and hopefully this will allay student fears of disadvantage.

The module also incorporated a self and peerassessment component which was a new concept for most of the students. One of the goals of our new module is to move towards supporting students to develop into "reflective practitioners" who are able to reflect critically upon their own professional practice $[7,8,9]$ This was in an effort to evaluate i) meta-cognitive competencies such as self- and peer-competencies, reflection and evaluation ii) social competencies such as instigating, organising and driving the discussion forums. Students received training on this method of assessment in advance. Early studies of this method of assessment warned of lack of validity. An early study by Dancer \& Dancer [10] suggested that students tended to mark in favour of friends. Measures were put in place to detect and minimize the effect of marking for factors other than merit. Firstly each group of four was given a total of 8 marks to divide up amongst the four contributors This improved previous efforts at peer assessment whereby students were asked to mark each contributor on a percentage basis. With a limited number of marks to go around it was very clear that the students were less likely to give marks out of friendship or due to other non-academic qualities. Each mark given to one student was a mark less either for themselves or for a very good group member. This variation has been very successful. In addition we have incorporated an additional check to establish the validity of the evaluation system. When any student's marks vary significantly from the other group members that student is called to the academic tutor and asked to explain the distribution. This has been necessary in only approximately $1 \%$ of the total peer evaluations that we have conducted. Less than $10 \%$ of the students were against this concept. The benefit of incorporating this into the module was obvious to most students as the research phase of the module progressed. It was clear to them that they had a mechanism by which marks were awarded reflecting the personal efforts of the individuals in the group.

\section{Conclusion}

The introduction of the debate module has brought many definite advantages to the programme. All of our students are introduced to the concept of researching a scientific subject and experiencing the concept of critically analysing it from the first year of the course. They put into practice the skills of literature search that they had learned earlier in the year. Through careful and continuous mentoring in advance of the debates they learned to distinguish reliable sources of information from those that could not be used and so use the skills of literature search that they had learned in semester one. These two skills alone are 
lifelong skills to be honed and we believe that this experience has given the students a head start on that process.

Equally importantly the debate module had accomplished another task. It has improved the first year experience for $90 \%$ of this student cohort. They developed a sense of camaraderie, they met with all members of the class and they interacted one on one with a faculty member which gave them a sense of belonging. All of the students were obliged to attend all of the debates and were given a small \% of the marks for that. It is our intention to continue to monitor the performance of this student cohort and compare academic performance with previous groups who have not been exposed to this experience.

The practice of incorporating self- and peer assessment into this module has been very rewarding and we believe a very positive experience for all the students. The design of our practice of dividing up a limited number of marks has contributed most to the success of the evaluation. To date this component of the evaluation is anonymous in so far as students are unaware of the evaluation of other group members. It was our belief that openness might be too difficult for first year university students still struggling to establish themselves in a new environment. However, it is an process that we intend to explore in the near future. It is our belief that students, faced with having to explain openly their allocation of grades would do so according to effort solely. It is also our belief that students would make a greater collective contribution in an effort to avoid to being singled out in an open evaluation session.

In an age where access to information is so easy one of the key skills that sets a student apart from the rest is the ability to think critically. We believe that introducing debates from the first year of their course will improve this ability in all students and will do so in a fun way. It also builds character in the students; they have to think on the spot during the cross-examination, they have to listen to the other team and come up with a question to crossexamine the opposing team. All of these are invaluable life skills in addition to the process of the learning. As a result of our initial experiment we will be continuing with this module in the coming year and hope to expand it to other years of the course.

\section{References}

[1] West,T.L. The effects of argumentation instruction on critical thinking skills (Doctoral dissertation, Southern Illinois University at Carbondale, 1994). Dissertations Abstract International,(1994), 56/01, 35.

[2] Burton, E. J. Small group debates and the move towards a learner centred education (Masters Thesis, University of Guelph (Canada), 1996) 1996,34/06,2147.

[3] Steiner, S., Brzuzy, S., Gerdes, K. \& Hurdle, D. Using structured controversy to teach diversity content and cultural competence. Journal of Teaching in Science Work (2003) Journal of Teaching in Social Work, 23(1/2), 55-71.

[4] Koklanaris, N. et al.,Debate preparation/participation: An active, effective learning tool.(2008) Teaching and Learning in Medicine (2008), 20(3), 235-238.

[5] Omelicheva, M.Y., \& Avdeyeva, O. Teaching with lecture or debate? Testing the effectiveness of traditional versus active learning methods of instruction. PS: Political Science and Politics (2008), 41, 603-607.

[6] Lincoln, A. Political debates between Abraham Lincoln and Stephen A. Douglas in the celebrated campaign of 1858 in Illinois. .Cleveland: Burrows Bros. Co. 1857; Bartleby.com 2001.

[7] Schon, D.A. Educating the Reflective Practitioner: towards a new design for teaching and learning in the professions (San Francisco, CA, Jossey-Bass) (1987).

[8] Falchikov,N . \& Boud, D. Studnet self-assessement in higher education: A meta analysis, Review of Educational Research, 59, pp. 177-189 (1989).

[9] Kwan, K. \& Leung, R. Tutor versus peer group assessment of student performance in a simulation training exercise, Assessment and Evaluation in Higher Education, 21, pp. 178-192 (1996).

[10] Dancer, W.T. \& Dancer, J. Peer rating in higher education, Journal of Education for Business, 67, 99. 306-309 (1992). 